Functional hemispheric asymmetry and nicotine dependency as variables mediating neurobiological vulnerability to schizotypy in a non-clinical population of college students

\title{
Functional hemispheric asymmetry and nicotine dependency as variables mediating neurobiological vulnerability to schizotypy in a non-clinical population of college students
}

\author{
Eirini Zartaloudi ${ }^{1,2}$; Anna Polemikou ${ }^{3,4}$ \\ ${ }^{1}$ Division of Psychiatry, University College London, London, UK \\ ${ }^{2}$ School of Life and Medical Sciences, University of Hertfordshire, Hertfordshire, UK \\ ${ }^{3}$ School of Medicine, National \& Kapodistrian University of Athens, Athens, Greece \\ ${ }^{4}$ School of Humanities, University of the Aegean, Rhodes, Greece
}

\begin{abstract}
In the present study, schizotypal personality traits and their neuropsychological correlates were examined among a nonclinical sample, so as to gain insight into the variables mediating neurobiological vulnerability to schizotypy. To that effect, 50 young adults completed the Oxford-Liverpool Inventory of Feelings and Experiences, the Fagerström Test of Nicotine Dependence, the Edinburgh Handedness Questionnaire, and a dichotic listening task. Analyses revealed a significant righthemisphere dominance association to positive schizotypy, and a left-hemisphere dominance association to negative schizotypy. Nicotine dependence emerged as a significant correlate of positive and overall schizotypy, and lefthemisphere dominance. Gender-based interactions were significant for females on positive schizotypy, nicotine dependence and right-hemisphere dominance, and on negative schizotypy for males. The findings of this study can be used to advance our understanding of the factors of risk and resilience in the schizophrenia spectrum.
\end{abstract}

Keywords: brain laterality; schizotypy; psychosis proneness; psychotropic 
Functional hemispheric asymmetry and nicotine dependency as variables mediating neurobiological vulnerability to schizotypy in a non-clinical population of college students

\section{Introduction}

Significant evidence suggests a relation between two apparently different phenomena arising from two diverse scientific fields: schizotypy from the field of psychopathology, and brain laterality from the field of neuropsychology (Weinstein \& Graves, 2002). Schizotypy, particularly in a clinical context, is treated as a pathological condition (Mohr \& Claridge, 2015). Meehl (Meehl \& E., 1962) introduced schizotypy as a genetic diathesis-stress model, portraying the nature of the individual's latent proneness to schizophrenia (Lenzenweger \& Korfine, 1992). Schizotypy is a condition characterised by mild psychotic-like symptoms. In non-clinical populations, schizotypal symptoms are quantitatively sub-clinical, yet qualitatively analogous, to those of schizophrenia (Barnett \& Corballis, 2002; Premkumar et al., 2012). In other words, the construct represents a latent personality organization that harbours the liability for schizophrenia (Lenzenweger, 2006). Schizotypy prevalence is estimated at .6 to 1.1 percent of the general population (Lenzenweger, 2008).

Schizotypy is commonly assessed via self-report questionnaires, representing a dimensional approach to psychotic-like symptoms in dimensions known from the schizophrenia taxonomy; namely, positive [PS], negative [NS], and disorganized or cognitive disorganization [CogDis] schizotypy (Herzig et al., 2015). Popular measures include the Oxford Liverpool Inventory of Feelings and Experiences (O-LIFE; Oldfield, 1971), the Magical Ideation Scale (MI; Eckblad \& Chapman, 1983) and the Schizotypy Personality Questionnaire (SPQ; Raine, 1991). Higher scores connote higher proneness to psychosis, displaying symptoms akin to those of schizophrenia patients, as well as similar cognitive (Buchy, Woodward, \& Liotti, 2007), sensory-motor (Lenzenweger \& Gold, 2000), neurophysiological (Mohanty et al., 2005; Shenton, Dickey, Frumin, \& McCarley, 2001) and neurobiological (Murray, Lappin, \& Di Forti, 2008) irregularities.

A partial, at least, aetiological overlap between schizotypy and schizophrenia presents a viable and congruent approach towards expanding our understanding of schizophrenia spectrum disorders. In lieu of established similarities and points of departure between the two constructs, it comes as no surprise that current scientific research is geared towards 
Functional hemispheric asymmetry and nicotine dependency as variables mediating neurobiological vulnerability to schizotypy in a non-clinical population of college students

deepening an understanding of their underlying mechanisms (Lenzenweger \& Korfine, 1992). Additionally, research on schizotypy offers a structured model of research observation by eliminating confounding effects of medication in schizophrenia patients. Moreover, research in schizotypy is of importance in its own right, as elevated schizotypy has been associated with substance misuse (Skosnik, Spatz-Glenn, \& Park, 2001; Williams, Wellman, \& Rawlins, 1996) and disturbances across educational, professional, emotional and social facets of one's life (Cohen, Mohr, Ettinger, Chan, \& Park, 2015). Increasing our understanding of the mechanisms underlying the aforementioned disturbances could facilitate the evolution of intervention strategies (Ettinger et al., 2015).

\subsection{Schizotypy risk factors: Psychoactive (or psychotropic) substances}

Converging evidence supports the idea that psychotropic substance consumption, such as cannabis (Barkus, Stirling, Hopkins, \& Lewis, 2006; Barnes, Mutsatsa, Hutton, Watt, \& Joyce, 2006; Skosnik et al., 2001) and nicotine (de Leon, Diaz, Rogers, Browne, \& Dinsmore, 2002; Esterberg, Goulding, McClure-Tone, \& Compton, 2009) heavily influence the trajectories of both schizotypal and schizophrenic taxonomies. The relationship between dopamine-enhancing drugs (i.e. nicotine) and psychotic symptoms has been examined in both clinical and non-clinical populations, confirming the deterioration of positive psychotic symptoms in the former, and the instigation of psychosis in the latter (Moore et al., 2007; Sekine et al., 2001; Smith et al., 2009). Hence, enhanced dopaminergic activity has unsurprisingly been associated with schizophrenia spectrum disorders (Liouta, Smith, \& Mohr, 2008). In construction of an exploratory model, we can assume nicotine acting as a possible mediating environmental factor, imitating the effects of typical neurobiological vulnerability to schizophrenia-related disorders.

\subsection{Schizotypy and functional brain laterality}

Brain laterality with left-hemisphere dominance (LHD) in language processing and selective attention tasks, and righthemisphere dominance (RHD) in face recognition tasks, which have been reported in healthy populations seem to be diminished in both schizophrenia and schizotypy (Cohen \& Davis, 2009; Suzuki \& Usher, 2009). Inconsistencies regarding the relation of schizotypal dimensions and brain laterality exist in research, with some studies associating PS or CogDis with RHD (Herzig, Tracy, Munafò, \& Mohr, 2010; Leonards \& Mohr, 2009; Mohr \& Claridge, 2015; Suzuki \& Usher, 2009), others with LHD (Liouta et al., 2008; Mason \& Claridge, 1999), whereas some studies report no laterality at all (Gooding \& Braun, 2004; Herzig et al., 2010; Najt, Bayer, \& Hausmann, 2012).

Several factors might account for the heterogeneity of the aforementioned findings. The scale employed to evaluate schizotypy seems to play a role (Liouta et al., 2008; Schofield \& Mohr, 2014), since so far studies employing the MI scale have reported RHD (Mohr et al., 2005; Weinstein \& Graves, 2002), whereas studies with the O-LIFE inventory have reported either RHD (Suzuki \& Usher, 2009) or LHD (Liouta et al., 2008). Additionally, studies differ in terms of the laterality task utilised to assess brain laterality, with some using LHD tasks like dichotic listening tasks and lexical decision tasks, whereas others use RHD tasks like visual face processing tasks. It should be noted that so far only two studies have 
Functional hemispheric asymmetry and nicotine dependency as variables mediating neurobiological vulnerability to schizotypy in a non-clinical population of college students

employed both a RHD and a LHD laterality task and have found no significant relation between PS and brain laterality (Herzig et al., 2010; Schofield \& Mohr, 2014).

Furthermore, findings are likely prone to gender differences: females have been found to score higher on PS, whereas males commonly score higher on NS (Miettunen \& Jaaskelainen, 2010; Paíno-Piñeiro, Fonseca-Pedrero, Lemos-Giráldez, \& Muñiz, 2008).

Another possible explanation of the inconsistent findings reported in the literature pertains to the elevated consumption of psychotropic substances (e.g. nicotine) commonly observed in schizophrenia populations. Herzig and associates (2010) recently examined the interaction between schizotypy, nicotine consumption and dependence on brain laterality, and demonstrated a RHD with elevated nicotine dependence, despite brain laterality having been found unrelated to nicotine consumption.

\subsection{Aims and Hypotheses}

The aim of the present study was to examine the association between self-reported schizotypy, nicotine dependence and brain laterality in a non-clinical population. Due to the high heterogeneity of past findings, the pursuit of forming a definitive hypothesis was challenging. Nonetheless, we expected to find a significant relation between RHD and both PS and CogDis. No association was expected between NS and brain laterality. Regarding nicotine dependence, it was expected that higher nicotine dependence would be associated with elevated PS and brain laterality with RHD.

\section{Method}

\subsection{Ethics \& Procedure}

The project was reviewed by the Health and Human Sciences Ethics Committee with Delegated Authority and was allowed to proceed. The study was described in full to the participants, who were informed of the voluntary character of their participation and freely consented to participate.

\subsection{Participants}

Fifty students were recruited randomly on the basis of their presence at the campus of the Independent Science and Technology (IST) College in Athens, Greece. Ages ranged from 18 to 31 years (22.82 $\pm 2.82 ; 22.72 \pm 2.59$ for females; 22.92 \pm 2.89 for males), with a female to male ratio of 1:1. Inclusion criteria consisted of (i) English fluency, (ii) right-hand dominance and (iii) normal auditory capacity. Left-handed and ambidextrous subjects were excluded to minimize the possibility of introducing reduced brain asymmetry -due to handedness- as a confounding variable. By large, RHD is known to reflect the typical structural pattern of cerebellar asymmetry (right > left cerebellar hemisphere), whereas other types of handedness have been reported to represent a reduced or ipsilateral brain asymmetry (Papaeiliou, Polemikou, \& Michaelides, 2012). Auditory function was further screened using the online audiogram hearing test (Pigeon, 2007), to 
Functional hemispheric asymmetry and nicotine dependency as variables mediating neurobiological vulnerability to schizotypy in a non-clinical population of college students

exclude any possibility of including participants with undiagnosed hearing impairments. Only subjects whose auditory threshold was higher than the clinical range $(>10 \mathrm{~dB})$ were included in the present study. Any participants who selfdisclosed a family history of psychiatric or neurological illness, recent head trauma or substance misuse were also excluded.

\subsection{Instruments}

The following assessment instruments were used in the following order of application: Audiogram hearing test, EHI, OLIFE, FTND and a dichotic listening task.

\subsubsection{Oxford-Liverpool Inventory of Feelings and Experiences (O-LIFE)}

The O-LIFE questionnaire was used to evaluate schizotypal traits. The O-LIFE is a validated tool of 150 self-report items measuring psychosis-proneness (Mason \& Claridge, 2006; Mason, Claridge, \& Jackson, 1995). The instrument, which consists of four subscales, ranks high on internal consistency, ranging from $r=0.72$ to $r=0.89$ between the subscales (Mason et al., 1995) and test-retest reliability, ranging from $r=0.76$ to $r=0.93$ (Burch, Steel, \& Hemsley, 1998). PS is measured by 30 questions associated with magical thinking, paranoid ideation and hallucinatory experiences. CogDis is measured by 24 questions assessing lack of concentration, social anxiety and decision-making. NS is measured by 27 questions assessing the absence of delight from social and physical interactions. The fourth subscale evaluates Impulsive Nonconformity [IN] comprises of 23 items assessing bizarre behaviour and self-control deficiency. The aforementioned traits are not typically associated with schizotypy per se (Liouta et al., 2008), thus the scores yielded from the IN subscale were deemed unrelated to the purposes of the present study and, as such, were extracted from further analysis. All questions require yes/no responses (scored as $+1 / 0$, respectively). According to the instrument's creators, responses 55 , 58-59, 62, 66-69, 71, 74-78 and 80 are reverse-coded; they were, thus, scored accordingly (Mason \& Claridge, 2006). Scores for the three first subscales were calculated by summing item responses on each subscale separately. Overall schizotypy scores were obtained by summing the scores of the three subscales. Higher scores connoted higher levels of schizotypy. The three subscales of the O-LIFE questionnaire demonstrated a robust internal structure (Cronbach's $\alpha=.71$ ).

\subsubsection{Fagerström Test of Nicotine Dependence (FTND)}

FTND was used to assess nicotine dependence (Heatherton, Kozlowski, Frecker, \& Fagerström, 1991). FTND self-reports of cigarette smoking behaviour are measured along 6 items designed to measure the quantity of cigarette consumption, compulsion to use and dependence. Yes/no items are scored 0 or 1 , and multiple-choice items are scored from 0 to 3 , on 4-point Likert scale. Summed items yield a total score of 0-10. The individual's intensity of physical dependence on nicotine is scored high or low, accordingly; $(1-2=$ low, $3-4=$ low to moderate, 5-7 = moderate, 8 and above $=$ high nicotine dependence). The 6 items of FTND yielded a high internal consistency $(\alpha=.86)$.

\subsubsection{Edinburgh Handedness Inventory (EHI)}

Although participants disclosed their hand preference during the recruitment phase, the EHI (Oldfield, 1971) was also administered as an additional confirmatory measure. The EHI includes 12 items, covering an array of lateralized, uni- 
Functional hemispheric asymmetry and nicotine dependency as variables mediating neurobiological vulnerability to schizotypy in a non-clinical population of college students

manual daily activities (e.g. writing, drawing, throwing) and hand dominance is established based on participants' selfreported preference in completing them. Subjects place check marks under 'Left' or 'right' to denote their hand preference ( right $=+1$, left $=-1$, both $=0$ ), yielding a summed score of -12 to -12 . Elevated scores indicated a stronger right-handedness. Forty three out of 50 subjects displayed complete right-hand preference. The remaining subjects $(n=$ 7) lacked a clear preference for two out of 12 actions (both hands), though they reported performing the rest solely with their right hands. Therefore, for those participants, a strong (albeit not extreme) dextrality can be safely assumed. Internal consistency for the 12 items of the EHI was excellent $(\alpha=.88)$.

\subsubsection{Dichotic Listening Task}

Brain laterality was measured by means of the Dichotic Listening Task. A Shure SM7B microphone and a Focusrite Octopre MkII microphone preamplifier were used for the recordings. Six nonsense syllables were presented, articulated by a prerecorded female voice. Of those, three consisted of voiced $(b, d, g)$ and three of unvoiced $(k, p, t)$ consonants, paired with the vowel "a". Thirty unique pair combinations emerged from the initial 6 syllables (See Supplementary table 4). Each combination was presented to participants three times. Therefore, each participant listened to 90 stimuli presentations through stereo handsets plugged into the computer audio jack. A different pair of syllables was presented acoustically every five seconds. To avoid the effect of voice onset time, the Cool Edit software was used to ensure that both stimuli were presented simultaneously. At the same time another consonant-vowel syllable was presented visually, against a grey background on a computer screen. Following each trial, participants were asked to indicate whether the syllable they had seen was identical to the syllable they listened by their right or left ear, and to circle the appropriate word ("left" or "right") in a table they were provided with. The total of correct left hits, correct right hits, and correct total hits was calculated for each participant.

\subsection{Data Analysis}

The R Project for Statistical Computing, version 3.3.2, was used to execute all analyses. To employ a sensitive measure to side-favoring in lateralized task paradigms, a laterality index score for the dichotic listening task was calculated by subtracting the left hits (LH) from the right hits $(\mathrm{RH})$ and dividing the difference by the sum of total hits (RH-LF/ TH) (Liouta et al., 2008; Marshall, Caplan, \& Holmes, 1975). Positive values in the laterality index indicated left-hemisphere dominance (LHD), whereas negative values indicated right-hemisphere dominance (RHD). This index was employed in all the subsequent analyses for brain laterality. Shapiro-Wilk tests of normality indicated that data from both behavioural and schizotypy dimension tests were normally distributed ( $w$-values $>.9$ and $p$-values $>.5$ ). When we examined for skewness and kurtosis values ranged from -0.8 to 0.8 and -2.0 to 2.0 respectively.

\subsection{Design}

One-way ANOVAs with gender as a grouping factor for age, schizotypal dimensions, nicotine dependence and brain laterality were conducted. Pearson correlation analyses with laterality index, schizotypal dimensions and nicotine dependence scores were performed for the whole sample and for females and males separately. Finally, multiple linear 
Functional hemispheric asymmetry and nicotine dependency as variables mediating neurobiological vulnerability to schizotypy in a non-clinical population of college students

regression analyses were conducted to examine whether schizotypy and nicotine dependence are significant predictors of brain lateralisation. Schizotypy and brain laterality were also examined as predictors of nicotine dependence. All $p$ values were two-tailed and the threshold of significance was set at .05 . All analyses were adjusted for gender and age. A power analysis revealed that with a sample size of 50 , threshold of significance at 0.05 and threshold of statistical power at 0.8 , the minimum detectable effect size was $r=.38$.

\section{Results}

Descriptive statistics for the Edinburgh Handedness inventory, the Fagerström Test of Nicotine Dependence, the OxfordLiverpool Inventory of Feelings and Experiences and the dichotic listening task are presented in Table 1.

Table 1. Group means and SD of values on each instrument arranged collectively (total sample) and by gender.

\begin{tabular}{lcccccccc}
\hline Measure & \multicolumn{2}{c}{$\begin{array}{c}\text { Total } \\
(\mathrm{n}=50)\end{array}$} & $\begin{array}{c}\text { Females } \\
(\mathrm{n}=25)\end{array}$ & $\begin{array}{c}\text { Males } \\
(\mathrm{n}=25)\end{array}$ & F-values & $\begin{array}{c}\text { Effect size } \\
\text { (Cohen's } d)\end{array}$ \\
\hline Schizotypy $^{*}$ & 34.78 & \pm 6.65 & 34.64 & \pm 7.42 & 34.92 & \pm 5.90 & .02 & -.04 \\
Positive schizotypy $^{*}$ & 12.86 & \pm 4.09 & 15.24 & \pm 3.53 & 10.48 & \pm 3.10 & 25.42 & 1.43 \\
Negative schizotypy $^{*}$ & 11.24 & \pm 4.30 & 8.92 & \pm 3.73 & 13.56 & \pm 3.56 & 20.25 & -1.27 \\
Cognitive disorganization $^{*}$ & 10.68 & \pm 2.48 & 10.48 & \pm 2.5 & 10.88 & \pm 2.49 & .32 & -.16 \\
Nicotine dependence $^{* *}$ & 2.78 & \pm 1.95 & 3.76 & \pm 1.64 & 1.80 & \pm 1.76 & 16.64 & 1.15 \\
Right hits $^{\dagger}$ & 13.68 & \pm 3.32 & 12.12 & \pm 3.02 & 15.24 & \pm 2.88 & 14.00 & -1.06 \\
Left hits $^{\dagger}$ & 14.90 & \pm 4.18 & 16.44 & \pm 4.51 & 13.36 & \pm 3.21 & 7.73 & .79 \\
Handedness $^{\ddagger}$ & 11.82 & \pm .48 & 11.8 & \pm .50 & 11.84 & \pm .47 & .085 & -.08
\end{tabular}

Notes. $\pm=$ standard deviation; ${ }^{*}=$ Oxford-Liverpool Inventory of Feelings and Experiences; ${ }^{* *}$ Fagerström Test of Nicotine Dependence; ${ }^{\dagger}=$ Dichotic listening task; ${ }^{\ddagger}=$ Edinburgh Handedness inventory.

A one-way ANOVA with gender as a grouping factor on age indicated no significant age (always in years, \pm SD) difference between female $(22.72 \pm 2.59)$ and male $(22.92 \pm 2.89)$ participants $[F(2,48)=.06, p=.80]$.

One-way ANOVAs with gender as a grouping factor on schizotypal dimensions, nicotine dependency and brain laterality yielded significant differences on PS, NS, nicotine dependency and brain laterality. Females scored higher on PS, nicotine 
Functional hemispheric asymmetry and nicotine dependency as variables mediating neurobiological vulnerability to schizotypy in a non-clinical population of college students

dependency and RHD, and males scored higher on NS. Differences in overall schizotypy, and CogDis did not yield statistically significant results.

Table2. Table displaying the ANOVASs with gender as a grouping factor on schizotypal dimensions, nicotine dependence and brain laterality.

\begin{tabular}{|c|c|c|c|c|c|c|}
\hline & Schizotypy & $\begin{array}{c}\text { Positive } \\
\text { schizotypy }\end{array}$ & $\begin{array}{l}\text { Negative } \\
\text { schizotypy }\end{array}$ & $\begin{array}{c}\text { Cognitive } \\
\text { disorganisation }\end{array}$ & $\begin{array}{c}\text { Nicotine } \\
\text { dependence }\end{array}$ & $\begin{array}{l}\text { Brain } \\
\text { laterality }\end{array}$ \\
\hline \multirow{2}{*}{ Gender } & $F(2,48)=.02$ & $F(2,48)=25.42$ & $F(2,48)=20.25$ & $F(2,48)=.32$ & $F(2,48)=16.64$ & $F(2,48)=17.67$ \\
\hline & $p=.88$ & $p \leq .001$ & $p \leq .001$ & $p=.57$ & $p \leq .001$ & $p \leq .001$ \\
\hline
\end{tabular}

Notes. Significant associations are presented in bold.

Correlation analyses were performed to examine the relation between schizotypal dimensions, nicotine dependency and laterality. Overall schizotypy was found to be highly associated with all three subscales (PS, NS, CogDis). Nicotine dependency was found to be positively correlated with overall schizotypy and PS and negatively associated with RHD. Additionally, PS was correlated with RHD, whereas NS was correlated with a LHD. The rest of the comparisons were not significantly correlated. The correlation analyses are presented on the subsequent table. Further analyses for females and males separately are presented in tables 4 and 5.

Table 3. Table displaying the correlation analyses between schizotypal dimensions, nicotine dependence and brain laterality.

\begin{tabular}{|c|c|c|c|c|c|}
\hline & Schizotypy & $\begin{array}{c}\text { Positive } \\
\text { schizotypy }\end{array}$ & $\begin{array}{l}\text { Negative } \\
\text { schizotypy }\end{array}$ & $\begin{array}{c}\text { Cognitive } \\
\text { disorganisation }\end{array}$ & $\begin{array}{c}\text { Nicotine } \\
\text { dependence }\end{array}$ \\
\hline \multirow[b]{2}{*}{ Positive schizotypy } & $r=.61$ & & & & \\
\hline & $p \leq .001$ & - & - & - & - \\
\hline \multirow[b]{2}{*}{ Negative schizotypy } & $r=.64$ & $r=-.09$ & & & \\
\hline & $p \leq .001$ & $p=.53$ & - & $\begin{array}{l}- \\
-\end{array}$ & - \\
\hline \multirow{2}{*}{$\begin{array}{l}\text { Cognitive } \\
\text { disorganization }\end{array}$} & $r=.55$ & $r=.15$ & $r=.14$ & - & _. \\
\hline & $p \leq .001$ & $p=.28$ & $p=.37$ & & \\
\hline \multirow[b]{2}{*}{ Nicotine dependence } & $r=.47$ & $r=.83$ & $r=-.13$ & $r=.11$ & \multirow[b]{2}{*}{ - } \\
\hline & $p \leq .001$ & $p<.001$ & $p=.18$ & $p=.46$ & \\
\hline \multirow{2}{*}{ Laterality } & $r=-.19$ & $r=-.59$ & $r=.29$ & $r=-.04$ & $r=-.49$ \\
\hline & $p=.18$ & $p \leq .001$ & $p=.04$ & $p=.75$ & $p \leq .001$ \\
\hline
\end{tabular}

Notes. Significant associations are presented in bold. 
Functional hemispheric asymmetry and nicotine dependency as variables mediating neurobiological vulnerability to schizotypy in a non-clinical population of college students

A multiple regression analysis was performed to examine whether scores in schizotypy and nicotine dependence could predict brain laterality. The enter method was employed and it was found that scores in schizotypy and nicotine dependence could explain a significant amount of variance in brain laterality. PS and NS were found to be significant predictors of brain laterality. Nicotine dependence and CogDis were not found to be significant predictors.

A second multiple regression analysis was performed to examine whether scores in schizotypy and brain laterality could predict nicotine dependence. The enter method was employed and it was found that scores in schizotypy and the laterality indices could explain a significant amount of variance in nicotine dependence. PS was found to be significant predictor of nicotine dependence. NS, CogDis and brain laterality were not found to be significant predictors. The following table displays the regression models.

Table 4 Table displaying the regression models.

\begin{tabular}{|c|c|c|c|c|}
\hline Model $1^{*}$ & \multicolumn{4}{|c|}{$F(4,45)=7.72, p \leq .001, \mathrm{R} 2=.64, \mathrm{R}^{2}$ adjusted $=0.35$} \\
\hline \multirow{4}{*}{ Laterality } & $\begin{array}{c}\text { Positive } \\
\text { schizotypy }\end{array}$ & $\begin{array}{l}\text { Negative } \\
\text { schizotypy }\end{array}$ & $\begin{array}{c}\text { Cognitive } \\
\text { disorganization }\end{array}$ & $\begin{array}{c}\text { Nicotine } \\
\text { dependence }\end{array}$ \\
\hline & Beta $=-.62$ & Beta $=.24$ & Beta $=.11$ & Beta $=.03$ \\
\hline & $t(49)=-2.90$ & $t(49)=2.06$ & $t(49)=.09$ & $t(49)=.25$ \\
\hline & $p \leq .01$ & $p=.0 .4$ & $p=.92$ & $p=.80$ \\
\hline Model $2^{* *}$ & \multicolumn{4}{|c|}{$F(4,45)=27.02, p \leq .001, \mathrm{R} 2=.84, \mathrm{R}^{2}$ adjusted $=0.68$} \\
\hline \multirow{4}{*}{$\begin{array}{l}\text { Nicotine } \\
\text { dependence }\end{array}$} & $\begin{array}{l}\text { Positive } \\
\text { schizotypy }\end{array}$ & $\begin{array}{l}\text { Negative } \\
\text { schizotypy }\end{array}$ & $\begin{array}{c}\text { Cognitive } \\
\text { disorganization }\end{array}$ & Laterality \\
\hline & Beta $=.85$ & Beta $=-.06$ & Beta $=-.01$ & Beta $=.03$ \\
\hline & $t(49)=8.36$ & $t(49)=-.68$ & $t(49)=-.18$ & $t(49)=.25$ \\
\hline & $p \leq .001$ & $p=.50$ & $p=.86$ & $p=.80$ \\
\hline
\end{tabular}

Notes. "Model 1: Predictors:

Schizotypal dimensions and Nicotine Dependence. Outcome: Laterality; ${ }^{* *}$ Model 2: Predictors: Schizotypal dimensions and Laterality. Outcome: Nicotine Dependence. Significant associations are presented in bold.

\subsection{Gender-based Interactions}

Pearson's correlations were performed separately for male and female participants to examine the relationship between gender membership and (i) nicotine dependency, (ii) laterality, and (iii) different schizotypy subscale scores (namely: overall, PS, CogDis and NS).

\subsection{Brain laterality and Nicotine dependency}

Insofar as the relationship between brain laterality and nicotine dependency was concerned, results yielded an inverse moderate correlation amongst both female and male participants, indicating RHD.

\subsection{Nicotine dependency correlations with schizotypal dimensions}


Functional hemispheric asymmetry and nicotine dependency as variables mediating neurobiological vulnerability to schizotypy in a non-clinical population of college students

For female participants, nicotine dependence produced moderate to strong positive correlations with all schizotypy dimensions. With regards to male participants, nicotine dependency produced positive correlations with schizotypy, ranging from moderate in the overall dimension, to strong, as evidenced in the PS dimension.

\subsection{Brain laterality correlations with schizotypal dimensions}

For female participants, inverse correlations, indicating LHD, emerged as a function of the association between brain laterality and two schizotypy dimensions. Specifically: overall schizotypy and PS. Statistically non-significant associations emerged for their male counterparts.

Table 5. Table displaying the correlation analyses between schizotypal dimensions, nicotine dependence and brain laterality only for females.

\begin{tabular}{|c|c|c|c|c|c|}
\hline & Schizotypy & $\begin{array}{c}\text { Positive } \\
\text { schizotypy }\end{array}$ & $\begin{array}{l}\text { Negative } \\
\text { schizotypy }\end{array}$ & $\begin{array}{c}\text { Cognitive } \\
\text { disorganisation }\end{array}$ & $\begin{array}{c}\text { Nicotine } \\
\text { dependence }\end{array}$ \\
\hline Positive schizotypy & $\begin{array}{c}r=.85 \\
p \leq .001\end{array}$ & - & - & - & - \\
\hline Negative schizotypy & $\begin{aligned} r & =.80 \\
p & \leq .001\end{aligned}$ & $\begin{array}{c}r=.53 \\
p \leq .001\end{array}$ & - & - & - \\
\hline $\begin{array}{l}\text { Cognitive } \\
\text { disorganization }\end{array}$ & $\begin{aligned} r & =.57 \\
p & =.003\end{aligned}$ & $\begin{array}{l}r=.34 \\
p=.10\end{array}$ & $\begin{array}{l}r=.14 \\
p=.51\end{array}$ & - & - \\
\hline Nicotine dependence & $\begin{array}{l}r=.54 \\
p=.01\end{array}$ & $\begin{array}{c}r=.69 \\
p \leq .001\end{array}$ & $\begin{array}{l}r=.39 \\
p=.04\end{array}$ & $\begin{array}{l}r=.85 \\
p=.03\end{array}$ & - \\
\hline Laterality & $\begin{array}{l}r=-.48 \\
p=.02\end{array}$ & $\begin{array}{l}r=-.48 \\
p=.02\end{array}$ & $\begin{array}{l}r=-.25 \\
p=.21\end{array}$ & $\begin{array}{l}r=-.25 \\
p=.22\end{array}$ & $\begin{array}{l}r=.40 \\
p=.04\end{array}$ \\
\hline
\end{tabular}

Notes. Significant associations are presented in bold.

Table 6. Table displaying the correlation analyses between schizotypal dimensions, nicotine dependence and brain laterality only for males.

\begin{tabular}{lccccc}
\hline & Schizotypy & $\begin{array}{c}\text { Positive } \\
\text { schizotypy }\end{array}$ & $\begin{array}{c}\text { Negative } \\
\text { schizotypy }\end{array}$ & $\begin{array}{c}\text { Cognitive } \\
\text { disorganisation }\end{array}$ & $\begin{array}{c}\text { Nicotine } \\
\text { dependence }\end{array}$ \\
\hline Positive schizotypy & $r=.66$ & - & - & - \\
Negative schizotypy & $p \leq .001$ & $r=.70$ & $r=.12$ & - & - \\
Cognitive disorganization & $p \leq .001$ & $p=.58$ & & - \\
\end{tabular}


Functional hemispheric asymmetry and nicotine dependency as variables mediating neurobiological vulnerability to schizotypy in a non-clinical population of college students

$\begin{array}{lcclll} & \boldsymbol{p}=.004 & p=.45 & p=.69 & & \\ \text { Nicotine dependence } & \boldsymbol{r}=.58 & \boldsymbol{r}=.86 & r=.01 & r=.30 & \\ & \boldsymbol{p} \leq .001 & \boldsymbol{p} \leq .001 & p=.95 & p=.15 & \\ \text { Laterality } & r=-.18 & r=-.07 & \boldsymbol{r}=-.23 & r=-.01 & \boldsymbol{r}=-.49 \\ & p=.38 & p=.75 & \boldsymbol{p}=.25 & p=.95 & \boldsymbol{p} \leq .001\end{array}$

Notes. Significant associations are presented in bold.

\section{Discussion}

Insofar as the relationship between schizotypal dimensions and hemispheric lateralization is concerned, empirical findings in the existing literature have been far from unanimous. Previous studies have associate PS with RHD (Herzig et al., 2010; Leonards \& Mohr, 2009; Mohr \& Claridge, 2015; Suzuki \& Usher, 2009), others with LHD (Liouta et al., 2008; O. Mason \& Claridge, 1999) and yet others report no laterality at all (Gooding \& Braun, 2004; Herzig et al., 2010; Najt et al., 2012). Moreover, an overconsumption of psychoaffective substances in individuals with psychosis has been repeatedly demonstrated (de Leon et al., 2002; Esterberg et al., 2009; Herzig et al., 2010), which may account for the heterogeneity of the reported schizotypy and brain laterality associations. The present study examined the association between schizotypy and brain laterality, while accounting for age and gender differences, handedness and nicotine dependence.

Nicotine dependence yielded associations with overall schizotypy, PS and RHD. Our findings agree with previously conducted research reporting relations of psychoaffective substances with higher schizotypy (Herzig et al., 2010; Najt et al., 2012) and RHD (Ernst et al., 2001; Rose et al., 2007). To our knowledge, the only study to have also investigated schizotypy, nicotine dependence and brain laterality is the study by Herzig and associates (2010) in which nicotine dependence was indeed significantly associated with RHD. Since RHD is inversely associated with higher nicotine dependence, it is possible it could also be linked with overconsumption of other drugs (Degenhardt, Hall, \& Lynskey, 2001; Martínez-Ortega, Jurado, Martínez-González, \& Gurpegui, 2006) and other types of impulsive behaviours, for instance binge eating episodes or gambling (Cilia et al., 2008; Uher \& Treasure, 2005) assumed to contribute to reduction of asymmetry. For instance, along this line of thinking, Herzig et al. (2010) proposed that cannabis use may in fact balance rather than exacerbate uncommon hemispheric laterality patterns in schizophrenic patients. Similarly, Hahn, Neuhaus, Pogun et al. (2011) who examined altered laterality patterns in schizophrenia, reported a differential reduction of phonetic and emotional language asymmetries in a schizophrenic sample of men and women who smoked.

When gender differences were examined in our sample female participants scored significantly higher than males on nicotine dependence, which corroborates Berlin et al.'s (2003) findings of higher female FTND scores, possibly due to psychosocial factors, stimulation and tension alleviation. Nicotine dependence was significantly related to overall schizotypy, PS and NS in both genders. Nevertheless, we found associations between brain laterality, RHD, and FTND scores only on the female population. The phase of their menstrual cycle, which was unaccounted for, may partly explain these findings, as hemispheric dominance is known to transfer from left to right as the cycle progresses from the premenstrual to the menstrual phase (Heister, Landis, Regard, \& Schroeder-Heister, 1989) reaching laterality pattern akin 
Functional hemispheric asymmetry and nicotine dependency as variables mediating neurobiological vulnerability to schizotypy in a non-clinical population of college students

to that of males during menstruation (Hausmann, Slabbekoorn, Van Goozen, Cohen-Kettenis, \& Güntürkün, 2000). To substantiate our conclusion, we encourage further empirical research with heavy smokers where the effects of nicotine on behavior might prove to be more prevalent.

Furthermore, genetic studies point toward gender differentiations in the metabolism of nicotine, with women metabolising nicotine faster than men (Benowitz, Lessov-Schlaggar, Swan, \& Jacob, 2006) a factor which could potentially influence nicotine dependence. Several other factors such as autonomy, motivational drive and sociocultural norms have also been reported as influential in nicotine dependence (West \& Brown, 2013).

FTND is commonly recognized as a well validated and reliable instrument. It has been used across several countries, age groups (Prokhorov et al., 2000) and types of clinical and/or non-clinical populations (Buckley et al., 2005; Weinberger et al., 2007). Nevertheless, its sensitivity in detecting factors potentially influencing nicotine dependence has been questioned (Colby, Tiffany, Shiffman, \& Niaura, 2000; Steinberg, Williams, Steinberg, Krejci, \& Ziedonis, 2005)

With regards to schizotypal dimensions, previous research has provided inconsistent findings regarding the relation between PS and brain laterality (Herzig et al., 2010; Liouta et al., 2008; Najt et al., 2012; Schofield \& Mohr, 2014; Suzuki \& Usher, 2009). Nevertheless, the majority of studies agree that NS is not linked to brain laterality (Mason \& Claridge, 1999; Mohr et al., 2005; Schofield \& Mohr, 2014; Suzuki \& Usher, 2009; Weinstein \& Graves, 2002; Gooding \& Braun, 2004) whereas the study by Schofield and associates (2014) reports a significant relation with a left-hemisphere dominance. Regarding CogDis, once again, the existing literature is inconsistent with some studies reporting (i) an association with RHD (Herzig et al., 2010; Suzuki \& Usher, 2009), (ii) some LHD (Liouta et al., 2008; Schofield \& Mohr, 2014) or (iii) no association (Najt et al., 2012; Mason \& Claridge, 1999). In the current study the O-LIFE questionnaire was employed to assess PS, and preceding studies that have used O-LIFE have reported either RHD (Suzuki \& Usher, 2009) or LHD (Liouta et al., 2008). However, other studies with the MI scale seem to report only RHD (Mohr et al., 2005; Weinstein \& Graves, 2002). One of the major differences between the two scales is that O-LIFE includes more items assessing experiences, whereas the MI scales focuses more on beliefs (Schofield \& Mohr, 2014).

We found a significant relation between PS and RHD, and NS and LHD. Notwithstanding that dichotic listening is a right ear advantage (REA) task favouring LHD, which is associated with verbal processing (Hugdahl \& Wester, 1992), our findings further endorse the importance of addressing the implications of brain laterality in the scientific study of schizophrenia spectrum disorders. Any methodological concerns regarding the laterality task selected also apply to most past research conducted in the field which is, as reviewed above, sparse on this topic. Only two studies were identified: that of Herzig et al. (2010) and that of Schofield and Mohr (2014), neither of whom reported associations between schizotypal dimensions and brain laterality.

In our sample females scored higher in PS, whereas males scored higher in NS, which agrees with previous studies (Miettunen \& Jaaskelainen, 2010; Paíno-Piñeiro et al., 2008). When correlation analyses were run separately for males 
Functional hemispheric asymmetry and nicotine dependency as variables mediating neurobiological vulnerability to schizotypy in a non-clinical population of college students

and females, significant associations of overall schizotypy and PS with brain laterality, with RHD, were found only in females.

Given that the present study comprised of right-handed participants, and in view of the fact that the prevalence of righthandedness tends to be lower amongst individuals diagnosed with schizophrenia spectrum disorders (Somers, Sommer, Boks, \& Kahn, 2009), it would make sense to question whether the population under investigation may have been susceptible to psychosis from the onset. From that perspective, a pre-selection bias might seem plausible. Nonetheless, in an attempt to counteract any confounding variables related to brain laterality due to handedness, in most studies investigating schizotypy and brain laterality, right-handed subjects are commonly recruited (Herzig et al., 2010). Future studies could include right and left-handed participants so as to compare differences based on group membership (Herzig et al., 2010; Somers et al., 2009).

\section{Concluding remarks}

We have examined whether functional brain laterality, a behavioural marker of the psychosis spectrum, is reduced in individuals with high nicotine dependence and higher PS scores. Our findings confirm that individuals highly dependent on nicotine and with elevated PS scores exhibit RHD patterns. Further exploration of this relationship could potentially lead to the early detection of risk and/or resilience factors associated with psychosis proneness, and ultimately intensify the effectiveness of health education programmes, interventions, outcomes and lead to more favourable prognoses. Investigation of brain laterality could also expand our knowledge regarding developmental and/or behavioural markers that may increase one's liability for developing psychosis prior to its onset.

\section{Declaration of interest}

The authors declare that they have no competing interest.

\section{Contribution}

All authors have made significant contributions to this manuscript in the following areas: design of the study, data collection, data analysis and interpretation, drafting and revising the manuscript. All authors have given final approval of this manuscript.

\section{Funding}

This research did not receive any specific grant from funding agencies in the public, commercial, or not-for-profit sectors.

\section{References}

Barkus, E. J., Stirling, J., Hopkins, R. S., \& Lewis, S. (2006). Cannabis-induced psychosis-like experiences are associated 
Functional hemispheric asymmetry and nicotine dependency as variables mediating neurobiological vulnerability to schizotypy in a non-clinical population of college students

with high schizotypy. Psychopathology, 39(4), 175-178. https://doi.org/10.1159/000092678

Barnes, T. R. E., Mutsatsa, S. H., Hutton, S. B., Watt, H. C., \& Joyce, E. M. (2006). Comorbid substance use and age at onset of schizophrenia. The British Journal of Psychiatry, 188(3), 237-242.

https://doi.org/10.1192/bjp.bp.104.007237

Barnett, K. J., \& Corballis, M. C. (2002). Ambidexterity and magical ideation. Laterality: Asymmetries of Body, Brain and Cognition, 7(1), 75-84. https://doi.org/10.1080/13576500143000131

Benowitz, N., Lessov-Schlaggar, C., Swan, G., \& Jacob, P. (2006). Female sex and oral contraceptive use accelerate nicotine metabolism. Clinical Pharmacology \& Therapeutics, 79(5), 480-488.

https://doi.org/10.1016/j.clpt.2006.01.008

Berlin, I., Singleton, E. G., Pedarriosse, A.-M., Lancrenon, S., Rames, A., Aubin, H.-J., \& Niaura, R. (2003). The modified reasons for smoking scale: factorial structure, gender effects and relationship with nicotine dependence and smoking cessation in French smokers. Addiction, 98(11), 1575-1583. https://doi.org/10.1046/j.13600443.2003.00523.x

Buchy, L., Woodward, T., \& Liotti, M. (2007). A cognitive bias against disconfirmatory evidence (BADE) is associated with schizotypy. Schizophrenia Research, 90(1-3), 334-337. https://doi.org/10.1016/j.schres.2006.11.012

Buckley, T. C., Mozley, S. L., Holohan, D. R., Walsh, K., Beckham, J. C., \& Kassel, J. D. (2005). A psychometric evaluation of the Fagerström test for nicotine dependence in PTSD smokers. Addictive Behaviors, 30(5), 1029-1033. https://doi.org/10.1016/j.addbeh.2004.09.005

Burch, G. S. J., Steel, C., \& Hemsley, D. R. (1998). Oxford-Liverpool inventory of feelings and experiences: Reliability in an experimental population. British Journal of Clinical Psychology, 37(1), 107-108. https://doi.org/10.1111/j.20448260.1998.tb01284.x

Cilia, R., Siri, C., Marotta, G., Isaias, I. U., De Gaspari, D., Canesi, M., ... Antonini, A. (2008). Functional abnormalities underlying pathological gambling in parkinson disease. Archives of Neurology, 65(12), 1604-1611. https://doi.org/10.1001/archneur.65.12.1604

Cohen, A. S., \& Davis, T. E. (2009). Quality of life across the schizotypy spectrum: findings from a large nonclinical adult sample. Comprehensive Psychiatry, 50(5), 408-414. https://doi.org/10.1016/j.comppsych.2008.11.002

Cohen, A. S., Mohr, C., Ettinger, U., Chan, R. C. K., \& Park, S. (2015). Schizotypy as an organizing framework for social and affective sciences. Schizophrenia Bulletin, 41(2), S427-S435. https://doi.org/10.1093/schbul/sbu195

Colby, S. M., Tiffany, S. T., Shiffman, S., \& Niaura, R. S. (2000). Measuring nicotine dependence among youth: a review of available approaches and instruments. Drug and Alcohol Dependence, 59(1), 23-39. Retrieved from http://www.ncbi.nlm.nih.gov/pubmed/10773436 
Functional hemispheric asymmetry and nicotine dependency as variables mediating neurobiological vulnerability to schizotypy in a non-clinical population of college students

de Leon, J., Diaz, F. J., Rogers, T., Browne, D., \& Dinsmore, L. (2002). Initiation of daily smoking and nicotine dependence in schizophrenia and mood disorders. Schizophrenia Research, 56(1-2), 47-54. Retrieved from http://www.ncbi.nlm.nih.gov/pubmed/12084419

Degenhardt, L., Hall, W., \& Lynskey, M. (2001). Alcohol, cannabis and tobacco use among Australians: a comparison of their associations with other drug use and use disorders, affective and anxiety disorders, and psychosis. Addiction, 96(11), 1603-1614. https://doi.org/10.1080/09652140120080732

Eckblad, M., \& Chapman, L. J. (1983). Magical ideation as an indicator of schizotypy. Journal of Consulting and Clinical Psychology, 51(2), 215-225. https://doi.org/10.1037/0022-006X.51.2.215

Ernst, M., Matochik, J. A., Heishman, S. J., Van Horn, J. D., Jons, P. H., Henningfield, J. E., \& London, E. D. (2001). Effect of nicotine on brain activation during performance of a working memory task. Proceedings of the National Academy of Sciences of the United States of America, 98(8), 4728-4733. https://doi.org/10.1073/pnas.061369098

Esterberg, M. L., Goulding, S. M., McClure-Tone, E. B., \& Compton, M. T. (2009). Schizotypy and nicotine, alcohol, and cannabis use in a non-psychiatric sample. Addictive Behaviors, 34(4), 374-379.

https://doi.org/10.1016/j.addbeh.2008.11.007

Ettinger, U., Mohr, C., Gooding, D. C., Cohen, A. S., Rapp, A., Haenschel, C., \& Park, S. (2015). Cognition and brain function in schizotypy: A selective review. Schizophrenia Bulletin, 41(2), S417-S426.

https://doi.org/10.1093/schbul/sbu190

Gooding, D., \& Braun, J. G. (2004). Visuoconstructive performance, implicit hemispatial inattention, and schizotypy. Schizophrenia Research, 68(2-3), 261-269. https://doi.org/10.1016/S0920-9964(03)00157-9

Hahn, C., Neuhaus, A.H., Pogun, S., Dettling, M., Kotz, S.A., Hahn, E., Brüne, M., Güntürkün, O. (2011). Smoking reduces language lateralization: A dichotic listening study with control participants and schizophrenia patients. Brain and Cognition, 76(2), 300-309. doi.org/10.1016/j.bandc.2011.03.015

Hausmann, M., Slabbekoorn, D., Van Goozen, S. H. M., Cohen-Kettenis, P. T., \& Güntürkün, O. (2000). Sex hormones affect spatial abilities during the menstrual cycle. Behavioral Neuroscience, 114(6), 1245-1250.

Heatherton, T. F., Kozlowski, L. T., Frecker, R. C., \& Fagerström, K. O. (1991). The Fagerström test for nicotine dependence: a revision of the Fagerström tolerance questionnaire. British Journal of Addiction, 86(9), 1119-1127. Retrieved from http://www.ncbi.nlm.nih.gov/pubmed/1932883

Heister, G., Landis, T., Regard, M., \& Schroeder-Heister, P. (1989). Shift of functional cerebral asymmetry during the menstrual cycle. Neuropsychologia, 27(6), 871-880. Retrieved from http://www.ncbi.nlm.nih.gov/pubmed/2755595

Herzig, D. A., Sullivan, S., Lewis, G., Corcoran, R., Drake, R., Evans, J., ... Mohr, C. (2015). Hemispheric language asymmetry in first episode psychosis and schizotypy: The role of cannabis consumption and cognitive 
Functional hemispheric asymmetry and nicotine dependency as variables mediating neurobiological vulnerability to schizotypy in a non-clinical population of college students

disorganization. Schizophrenia Bulletin, 41(2), S455-S464. https://doi.org/10.1093/schbul/sbu179

Herzig, D. A., Tracy, J., Munafò, M., \& Mohr, C. (2010). The influence of tobacco consumption on the relationship between schizotypy and hemispheric asymmetry. Journal of Behavior Therapy and Experimental Psychiatry, 41(4), 397-408. https://doi.org/10.1016/j.jbtep.2010.04.003

Hugdahl, K., \& Wester, K. (1992). Dichotic listening studies of hemispheric asymmetry in brain damaged patients. International Journal of Neuroscience, 63(1-2), 17-29. https://doi.org/10.3109/00207459208986657

Lenzenweger, M. F. (2006). Schizotypy: An organizing framework for schizophrenia research. Current Directions in Psychological Science, 15(4), 162-166. https://doi.org/10.1111/j.1467-8721.2006.00428.x

Lenzenweger, M. F. (2008). Epidemiology of personality disorders. Psychiatric Clinics of North America, 31(3), 395-403. https://doi.org/10.1016/j.psc.2008.03.003

Lenzenweger, M. F., \& Gold, J. M. (2000). Auditory working memory and verbal recall memory in schizotypy. Schizophrenia Research, 42(2), 101-110. Retrieved from http://www.ncbi.nlm.nih.gov/pubmed/10742648

Lenzenweger, M. F., \& Korfine, L. (1992). Confirming the latent structure and base rate of schizotypy: A taxometric analysis. Journal of Abnormal Psychology, 101(3), 567-571. https://doi.org/10.1037/0021-843X.101.3.567

Leonards, U., \& Mohr, C. (2009). Schizotypal personality traits influence idiosyncratic initiation of saccadic face exploration. Vision Research, 49(19), 2404-2413. https://doi.org/10.1016/j.visres.2009.07.013

Liouta, E., Smith, A. D., \& Mohr, C. (2008). Schizotypy and pseudoneglect: a critical update on theories of hemispheric asymmetries. Cognitive Neuropsychiatry, 13(2), 112-134. https://doi.org/10.1080/13546800801936698

Marshall, J. C., Caplan, D., \& Holmes, J. M. (1975). The measure of laterality. Neuropsychologia, 13(3), 315-321. Retrieved from http://www.ncbi.nlm.nih.gov/pubmed/1161129

Martínez-Ortega, J. M., Jurado, D., Martínez-González, M. A., \& Gurpegui, M. (2006). Nicotine dependence, use of illegal drugs and psychiatric morbidity. Addictive Behaviors, 31(9), 1722-1729.

https://doi.org/10.1016/j.addbeh.2005.12.012

Mason, O., \& Claridge, G. (1999). Individual differences in schizotypy and reduced asymmetry using the chimeric faces task. Cognitive Neuropsychiatry, 4(4), 289-301. https://doi.org/10.1080/135468099395846

Mason, O., \& Claridge, G. (2006). The Oxford-Liverpool inventory of feelings and experiences (O-LIFE): Further description and extended norms. Schizophrenia Research, 82(2-3), 203-211. https://doi.org/10.1016/j.schres.2005.12.845

Mason, O., Claridge, G., \& Jackson, M. (1995). New scales for the assessment of schizotypy. Personality and Individual Differences, 18(1), 7-13. https://doi.org/10.1016/0191-8869(94)00132-C

Meehl, P. E., \& E., P. (1962). Schizotaxia, schizotypy, schizophrenia. American Psychologist, 17(12), 827-838. 
Functional hemispheric asymmetry and nicotine dependency as variables mediating neurobiological vulnerability to schizotypy in a non-clinical population of college students

https://doi.org/10.1037/h0041029

Miettunen, J., \& Jaaskelainen, E. (2010). Sex differences in wisconsin schizotypy scales--A meta-analysis. Schizophrenia Bulletin, 36(2), 347-358. https://doi.org/10.1093/schbul/sbn075

Mohanty, A., Herrington, J. D., Koven, N. S., Fisher, J. E., Wenzel, E. A., Webb, A. G., ... Miller, G. A. (2005). Neural mechanisms of affective interference in schizotypy. Journal of Abnormal Psychology, 114(1), 16-27. https://doi.org/10.1037/0021-843X.114.1.16

Mohr, C., \& Claridge, G. (2015). Schizotypy--Do not worry, it is not all worrisome. Schizophrenia Bulletin, 41(2), S436S443. https://doi.org/10.1093/schbul/sbu185

Mohr, C., Krummenacher, P., Landis, T., Sandor, P. S., Fathi, M., \& Brugger, P. (2005). Psychometric schizotypy modulates levodopa effects on lateralized lexical decision performance. Journal of Psychiatric Research, 39(3), 241-250. https://doi.org/10.1016/j.jpsychires.2004.08.006

Moore, T. H. M., Zammit, S., Lingford-Hughes, A., Barnes, T. R. E., Jones, P. B., Burke, M., \& Lewis, G. (2007). Cannabis use and risk of psychotic or affective mental health outcomes: a systematic review. Lancet, 370(9584), 319-328. https://doi.org/10.1016/S0140-6736(07)61162-3

Murray, R. M., Lappin, J., \& Di Forti, M. (2008). Schizophrenia: From developmental deviance to dopamine dysregulation. European Neuropsychopharmacology, 18(3), S129-S134. https://doi.org/10.1016/j.euroneuro.2008.04.002

Najt, P., Bayer, U., \& Hausmann, M. (2012). Atypical lateralisation in emotional prosody in men with schizotypy. Laterality: Asymmetries of Body, Brain and Cognition, 17(5), 533-548. https://doi.org/10.1080/1357650X.2011.586702

Oldfield, R. C. (1971). The assessment and analysis of handedness: the Edinburgh inventory. Neuropsychologia, 9(1), 97113. Retrieved from http://www.ncbi.nlm.nih.gov/pubmed/5146491

Paíno-Piñeiro, M., Fonseca-Pedrero, E., Lemos-Giráldez, S., \& Muñiz, J. (2008). Dimensionality of schizotypy in young people according to sex and age. Personality and Individual Differences, 45(2), 132-138. https://doi.org/10.1016/j.paid.2008.03.011

Papaeiliou, C., Polemikou, A., \& Michaelides, K. (2012). Bias in socio-cognitive and linguistic function in Williams Syndrome. In T. Dutta, S. Kumar, \& M. Mandal (Eds.), Bias in human behavior: perspectives on cognitive psychology (pp. 275-298). Hauppage, NY: Nova Science Publishers.

Pigeon, S. (2007). Online audiogram hearing test. Retrieved February 13, 2017, from http://www.audiocheck.net/testtones_hearingtestaudiogram.php

Premkumar, P., Ettinger, U., Inchley-Mort, S., Sumich, A., Williams, S. C. R., Kuipers, E., \& Kumari, V. (2012). Neural 
Functional hemispheric asymmetry and nicotine dependency as variables mediating neurobiological vulnerability to schizotypy in a non-clinical population of college students

processing of social rejection: The role of schizotypal personality traits. Human Brain Mapping, 33(3), 695-706. https://doi.org/10.1002/hbm.21243

Prokhorov, A. V, De Moor, C., Pallonen, U. E., Hudmon, K. S., Koehly, L., \& Hu, S. (2000). Validation of the modified Fagerström tolerance questionnaire with salivary cotinine among adolescents. Addictive Behaviors, 25(3), 429433. Retrieved from http://www.ncbi.nlm.nih.gov/pubmed/10890296

Raine, A. (1991). The SPQ: A scale for the assessment of schizotypal personality based on DSM-III-R criteria. Schizophrenia Bulletin, 17(4), 555-564. https://doi.org/10.1093/schbul/17.4.555

Rose, J. E., Behm, F. M., Salley, A. N., Bates, J. E., Coleman, R. E., Hawk, T. C., \& Turkington, T. G. (2007). Regional brain activity correlates of nicotine dependence. Neuropsychopharmacology, 32, 2441-2452. https://doi.org/10.1038/sj.npp.1301379

Schofield, K., \& Mohr, C. (2014). Schizotypy and hemispheric asymmetry: Results from two Chapman scales, the O-LIFE questionnaire, and two laterality measures. Laterality, 19(2), 178-200.

https://doi.org/10.1080/1357650X.2013.789883

Sekine, Y., Iyo, M., Ouchi, Y., Matsunaga, T., Tsukada, H., Okada, H., ... Mori, N. (2001). Methamphetamine-related psychiatric symptoms and reduced brain dopamine transporters studied with PET. American Journal of Psychiatry, 158(8), 1206-1214. https://doi.org/10.1176/appi.ajp.158.8.1206

Shenton, M. E., Dickey, C. C., Frumin, M., \& McCarley, R. W. (2001). A review of MRI findings in schizophrenia. Schizophrenia Research, 49(1-2), 1-52. Retrieved from http://www.ncbi.nlm.nih.gov/pubmed/11343862

Skosnik, P. D., Spatz-Glenn, L., \& Park, S. (2001). Cannabis use is associated with schizotypy and attentional disinhibition. Schizophrenia Research, 48(1), 83-92. Retrieved from http://www.ncbi.nlm.nih.gov/pubmed/11278156

Smith, G. N., Wong, H., MacEwan, G. W., Kopala, L. C., Ehmann, T. S., Thornton, A. E., ... Honer, W. G. (2009). Predictors of starting to smoke cigarettes in patients with first episode psychosis. Schizophrenia Research, 108(1-3), 258-264. https://doi.org/10.1016/j.schres.2008.12.013

Somers, M., Sommer, I. E., Boks, M. P., \& Kahn, R. S. (2009). Hand-preference and population schizotypy: A metaanalysis. Schizophrenia Research, 108(1-3), 25-32. https://doi.org/10.1016/j.schres.2008.11.010

Steinberg, M. L., Williams, J. M., Steinberg, H. R., Krejci, J. A., \& Ziedonis, D. M. (2005). Applicability of the Fagerström test for nicotine dependence in smokers with schizophrenia. Addictive Behaviors, 30(1), 49-59. https://doi.org/10.1016/j.addbeh.2004.04.012

Suzuki, A., \& Usher, M. (2009). Individual differences in language lateralisation, schizotypy and the remote-associate task. Personality and Individual Differences, 46(5-6), 622-626. https://doi.org/10.1016/j.paid.2009.01.006

Uher, R., \& Treasure, J. (2005). Brain lesions and eating disorders. Journal of Neurology, Neurosurgery, and Psychiatry, 
Functional hemispheric asymmetry and nicotine dependency as variables mediating neurobiological vulnerability to schizotypy in a non-clinical population of college students 76(6), 852-857. https://doi.org/10.1136/jnnp.2004.048819

Weinberger, A. H., Reutenauer, E. L., Allen, T. M., Termine, A., Vessicchio, J. C., Sacco, K. A., ... George, T. P. (2007). Reliability of the Fagerström test for nicotine dependence, Minnesota nicotine withdrawal scale, and Tiffany questionnaire for smoking urges in smokers with and without schizophrenia. Drug and Alcohol Dependence, 86/23), 278-282. https://doi.org/10.1016/j.drugalcdep.2006.06.005

Weinstein, S., \& Graves, R. E. (2002). Are creativity and schizotypy products of a right hemisphere bias? Brain and Cognition, 49(1), 138-151. https://doi.org/10.1006/brcg.2001.1493

West, R., \& Brown, J. (2013). Theory of addiction. West Sussex, UK: John Wiley \& Sons, Ltd.

Williams, J. H., Wellman, N. A., \& Rawlins, J. N. (1996). Cannabis use correlates with schizotypy in healthy people. Addiction, 91(6), 869-877. Retrieved from http://www.ncbi.nlm.nih.gov/pubmed/8696249 